Relations industrielles

Industrial Relations

\title{
Human Relations in Administration, by R. Dubin, Englewood Cliffs, N.J., Prentice-Hall, 1957.
}

\section{G. R. Giroux}

Volume 15, numéro 1, janvier 1960

URI : https://id.erudit.org/iderudit/1022079ar

DOI : https://doi.org/10.7202/1022079ar

Aller au sommaire du numéro

Éditeur(s)

Département des relations industrielles de l’Université Laval

ISSN

0034-379X (imprimé)

1703-8138 (numérique)

Découvrir la revue

Citer ce compte rendu

Giroux, G. (1960). Compte rendu de [Human Relations in Administration, by R. Dubin, Englewood Cliffs, N.J., Prentice-Hall, 1957.] Relations industrielles /

Industrial Relations, 15(1), 142-142. https://doi.org/10.7202/1022079ar

Tous droits réservés (C Département des relations industrielles de l’Université Laval, 1960
Ce document est protégé par la loi sur le droit d'auteur. L’utilisation des services d'Érudit (y compris la reproduction) est assujettie à sa politique d'utilisation que vous pouvez consulter en ligne.

https://apropos.erudit.org/fr/usagers/politique-dutilisation/ 
fisamment pris la peine de considérer attentivement le phénomène américain en utilisant des catégories qui pouvaient l'expliquer tel qu'il est. Il n'est d'ailleurs pas le seul à verser dans cette déformation.

Ces réserves, si importantes qu'elles soient, ne diminuent pas les mérites de certaines parties de l'ouvrage, en particulier de celles qui concernent les principes de la propriété privée, les bases d'un juste salaire, et le développement d'une organisation fonctionnelle.

\section{Gérard Dion}

\section{Human Relations in Administration,} by R. Dubin, Englewood Cliffs, N.J., Prentice-Hall, 1957.

Quand un lecteur aborde un volume dont le titre inclut les mots de relations humaines, il s'attend d'y trouver des enquêtes et entrevues sur le moral et les attitudes des employés, des statistiques sur l'âge, l'éducation, l'ancienneté, le roulement de la main-d'oeuvre, l'absentéisme, etc... et enfin des corrélations entre diverses mesures de satisfaction et de rendement. Cette méthode d'analyse s'appuie sur l'étude d'un seul segment de toute société ou organisation industrielle: l'employé. En général, elle ignore la structure même de l'organisation, les attributs qui la caractérisent et les individus qui l'animent: la gérance, les spécialistes et l'employé.

Justement ce volume de Dubin est probablement l'un des, premiers qui s'attaquent à l'étude d'une organisation industrielle en considérant sa structure et ses qualités distinctives. Nous ne sommes pas d'accord avec Dubin quand il affirme que cet ouvrage est basé sur la recherche. Il rapporte surtout les considérations et les expériences personnelles de chaque individu qui a collaboré à la préparation du volume. Ces collaborateurs sont surtout des sociologues.

Le présent ouvrage n'est pas récent puisqu'il fut imprimé d'abord pour la première fois en 1951 et que les références sont antérieures à cette année-là.

La première partie du volume se compose de 21 chapitres. Chacun d'eux comprend plusieurs articles rédigés par des auteurs différents. Comme le style et l'école sociologique varient d'un auteur à l'autre, la lecture du volume est ardue et plutôt difficile. En effet, le lecteur n'a pas le temps de s'adapter aux différents styles.

L'auteur décrit en premier lieu l'organisation en tant que système social et ensuite il considère les motivations évoquées par ce système. Les relations qui s'établissent alors entre les membres de cette organisation découlent des procédures inhérentes à la structure elle-même. La structure des différents systèmes administratifs fait l'objet de plusieurs chapitres, de même que les attributs des membres. Les articles sur les « exécutifs », les spécialistes et les contremaîtres pénètrent si bien les dynamiques en jeu que le lecteur acquiert un bon aperçu de toute la situation. Prendre des décisions, i.e. 《decision-making s est-il un art ou une science? Ici il n'est pas question de la science des décisions (Operations Research), mais de la variété des décisions et des limites imposées à la gérance par la structure de porganisation.

La deuxième partie du volume comprend uniquement des cas à discuter. Ces cas se rapportent surtout aux relations entre patrons et employés. $\mathrm{Hu}$ man Relations in Administration * serait surtout utile comme texte de base pour un cours ayant une période théorique suivie d'une période de discussion de cas.

\section{G. R. Graoux}

Compulsory Conciliation and Collective Bargaining, The New Brunswick Experience, by W. B. Cunningham. Published by The New Brunswick Department of Labour, Fredericton, N.B. and The Industrial Relations Centre, McGill University, Montreal, 123 pp.

Depuis quelques années, on assiste à un mouvement de plus en plus répandu d'examen et de critique du système de conciliation obligatoire à travers le Canada. Le présent ouvrage s'ajoute au dossier déjà impressionnant de l'analyse de cette forme d'intervention gouvernementale dans le règlement des conflits du travail. 